\title{
Nutrition for the Prevention and Treatment of Injuries in Track and Field Athletes
}

\author{
Graeme L. Close \\ Liverpool John Moores University \\ Keith Baar \\ University of California
}

\author{
Craig Sale \\ Nottingham Trent University \\ Stephane Bermon \\ Université Côte d'Azur
}

\begin{abstract}
Injuries are an inevitable consequence of athletic performance with most athletes sustaining one or more during their athletic careers. As many as one in 12 athletes incur an injury during international competitions, many of which result in time lost from training and competition. Injuries to skeletal muscle account for over $40 \%$ of all injuries, with the lower leg being the predominant site of injury. Other common injuries include fractures, especially stress fractures in athletes with low energy availability, and injuries to tendons and ligaments, especially those involved in high-impact sports, such as jumping. Given the high prevalence of injury, it is not surprising that there has been a great deal of interest in factors that may reduce the risk of injury, or decrease the recovery time if an injury should occur: One of the main variables explored is nutrition. This review investigates the evidence around various nutrition strategies, including macro- and micronutrients, as well as total energy intake, to reduce the risk of injury and improve recovery time, focusing upon injuries to skeletal muscle, bone, tendons, and ligaments.
\end{abstract}

Keywords: athletics, collagen, epidemiology, protein

In athletics, the epidemiology of injuries occurring before or during an international elite competition has been extensively described (Edouard et al., 2015, 2016; Feddermann-Demont et al., 2014). Unfortunately, there is less accurate information available when it comes to injuries occurring during training (out of competition) periods and/or in subelite or recreational athletes. In elite track and field athletes, there were approximately 81 injuries per 1,000 athletes registered to a World Championship (Feddermann-Demont et al., 2014), in other words, approximately one in 12 registered athletes will incur injury during International Athletics Championships. This is important since approximately half of these injuries will result in a time loss and absence from sports, including both training and competing (FeddermannDemont et al., 2014). Among these injuries, skeletal muscle is the principal type, accounting for $40.9 \%$ of all recorded injuries (Edouard et al., 2016), with $58 \%$ of these injuries resulting in time loss during the International Athletics Championships between 2007 and 2015. Hamstring injury is by far the most frequent injury (approximately 17\%), and it is more frequent (relative risk: 1.94) in male athletes than in female athletes. These hamstring injuries are more frequently described in sprinters, whereas overuse injuries of

Close is with the Research Institute for Sport and Exercise Sciences, Liverpool John Moores University, Liverpool, United Kingdom. Sale is with Musculoskeletal Physiology Research Group, Sport, Health and Performance Enhancement Research Centre, School of Science and Technology, Nottingham Trent University, Nottingham, United Kingdom. Baar is with the Dept. of Neurobiology, Physiology, and Behavior, University of California, Davis, CA; and Dept. of Physiology and Membrane Biology, University of California, Davis, CA. Bermon is with LAMHESS, Université Côte d'Azur, Nice, France; and Health and Science Dept., International Association of Athletics Federations, Monaco, Principality of Monaco. Close (g.1.close@ljmu.ac.uk) is corresponding author. the lower legs are more frequently reported in middle-long distance runners and race walkers. Elite female athletes experience more (relative risk: 3.1 ) stress fracture injuries than male athletes (Edouard et al., 2015), and this is explained by a higher incidence of Relative Energy Deficiency in Sport Syndrome (Mountjoy et al., 2014) and the associated reduced calcium absorption, fixation, and bone mineral density in this population.

Preparticipation predictors for Championships injury and illness have been identified (Timpka et al., 2017). For instance, athletes who reported an illness symptom causing anxiety before the competition were five times more likely to sustain an injury during the championships. Moreover, intensive training camps or tapering periods are often associated with increased stress and altered appetite response and decreased food intakes (both quantitative and qualitative aspects) in power-trained athletes. These findings attest to the important role that anxiety, stress, and their consequences play on the athlete's nutritional status and in the development of an injury during a major competition. Therefore, providing stress management and nutritional interventions as potential preparticipation interventions may reduce the onset of an acute injury is relevant.

Although injuries could be classed as a very likely outcome of sport, it is important to recognize that appropriate nutritional strategies have the ability to reduce the risk of injuries as well as enhance the recovery if an injury should occur. All athletes should engage with a properly qualified nutritionist who will promote a "food first approach" to prevent and treat injuries. Although the main preventative nutritional strategy will be to ensure adequate total energy intake and appropriate dietary intake, there are some supplements that have the potential to help. This review will focus on nutritional strategies to assist with the most common injuries, that is, skeletal muscle, bone, tendon, and ligament. We include a review of the extant literature that has 
looked at nutrition to prevent injuries and increase repair, as well as considering the change in energy requirements during the injury period.

\section{Nutrition to Prevent and Treat Muscle Injuries}

There is limited direct research on nutrition to prevent/treat muscle injuries, with most research originating from laboratory-induced muscle damage to study delayed onset muscle soreness (Owens et al., 2019). Although such studies provide insights into potential nutritional strategies, it must be stressed that there are substantial differences between delayed onset muscle soreness and a major muscle tear, both in terms of the structural damage, as well as the level of immobilization and unloading that may occur. However, given that there are no published placebo-controlled, randomized control trials on nutrition to prevent or treat muscle injuries following a "true" muscle injury in elite athletes, the laboratoryinduced muscle damage literature currently provides the best evidence base to help guide practice, while, of course, taking into consideration the limitations of this approach. From a nutrition perspective, it is important to consider the potential of nutrition to assist in injury prevention and prevent the loss of lean mass during immobilization, and to consider the change in energy requirements during the injury period along with any strategies that may promote muscle repair.

Given the crucial role of dietary protein in muscle protein turnover, it is not surprising that much attention has been given to dietary protein in the prevention of muscle injuries. It is accepted that the provision of dietary proteins enhances the adaptive processes to both resistance- and endurance-based exercise (Phillips \& Van Loon, 2011), and it is, therefore, attractive to hypothesize that increasing dietary protein may alleviate markers of muscle damage. However, the evidence to support this hypothesis is, at best, equivocal, with some studies reporting a benefit (Buckley et al., 2010; Cockburn et al., 2010; Nosaka et al., 2006), whereas others show no benefit (Blacker et al., 2010; Wojcik et al., 2001), albeit in laboratory-induced muscle damage studies. In a recent systemic review, the balance of the evidence suggested that protein supplements taken acutely, despite increases in protein synthesis and anabolic intracellular signaling, provide no measurable reductions in exercise-induced muscle damage and enhanced recovery of muscle function (Pasiakos et al., 2014). This lack of an effect may be explained by the differing time courses between an acute muscle injury and muscle protein turnover, with adaptations to muscle protein turnover being a relatively slow process (Tipton et al., 2003) compared with the rapid changes that occur following an injury. It can, therefore, be concluded that, given sufficient dietary protein is provided in the general diet of an athlete, additional protein intake will not prevent muscle injury or reduce postexercise muscle soreness. However, to date, this hypothesis has not been fully explored in elite athletes following a true injury and, therefore, case study data may help to provide further insights.

Although additional protein may not prevent a muscle injury, increased dietary protein may be beneficial after an injury both in terms of attenuating muscle atrophy and promoting repair. Limb immobilization reduces resting muscle protein synthesis as well as induces an anabolic resistance to dietary protein (Wall et al., 2013), although, again, it must be stressed that such studies are laboratory based and not following a true injury. This anabolic resistance can be attenuated (although not prevented) through increased dietary amino acid ingestion (Glover et al., 2008). It is beyond the scope of this manuscript to fully discuss what is appropriate protein intake for athletes and, for this, the reader is directed to several excellent reviews (e.g., Morton et al., 2018; Phillips, 2012; Stokes et al., 2018; Tipton \& Phillips, 2013). Contrary to popular belief, athletes engaged in whole-body resistance training are likely to benefit from more than the often cited $20 \mathrm{~g}$ of protein per meal, with recent research suggesting $40 \mathrm{~g}$ of protein may be a more optimum feeding strategy (Macnaughton et al., 2016). Protein intake should be equally distributed throughout the day, something that many elite athletes fail to achieve (Gillen et al., 2017), with many athletes consuming the majority of their protein in their evening meal, with less consumed at breakfast and lunch. In terms of an absolute amount of protein per day, increasing protein to $2.3 \mathrm{~g} / \mathrm{kg}$ body mass reduces the loss of lean body mass (LBM) during reduced calorie intake (Mettler et al., 2010), a strategy that could also prove useful for the injured athlete. Taken together, despite the limitations of the current literature base, injured athletes may benefit from increasing their protein intake to overcome the immobilization-induced anabolic resistance as well as helping to attenuate the associated losses of lean muscle mass documented in injured athletes (Milsom et al., 2014).

After a muscle injury, it is likely that athletic activities are reduced, if not stopped completely, to allow the muscle to recover, although some training in the noninjured limbs will likely continue. This reduction in activity results in reduced energy expenditure, which consequently requires a reduction in energy intake to prevent unwanted gains in body fat. Given that many athletes periodize their carbohydrate intake, that is, increase their carbohydrate intake during hard training days while limiting them during light training or rest days, it seems appropriate that during inactivity, carbohydrate intake may need to be reduced (Impey et al., 2018). It should be stressed, however, that the magnitude of the reduction in energy intake may not be as drastic as expected given that the healing process has been shown to result in substantial increases in energy expenditure (Frankenfield, 2006), whereas the energetic cost of using crutches is much greater than that of walking (Waters et al., 1987). Moreover, it is common practice for athletes to perform some form of exercise in the noninjured $\operatorname{limb}(\mathrm{s})$ while injured to maintain strength and fitness. It is, therefore, crucial that athletes do not reduce nutrition, that is, under fuel at the recovery stage through being too focused upon not gaining body fat; thus, careful planning is needed to manage the magnitude of energy restriction during this crucial recovery period. One thing that is generally accepted is that, when reducing energy intake, macronutrients should not be cut evenly as maintaining a high-protein intake will be essential to attenuate loss of lean muscle mass.

Poor attention has been paid to dietary lipids in the prevention of musculoskeletal injuries. In this context, mainly omega-3 polyunsaturated fatty acids (n-3 PUFA) have been studied because of their anti-inflammatory properties. Many studies have investigated the effects of n-3 PUFA supplementation on the loss of muscle function and inflammation following exercise-induced muscle damage, with the balance of the literature suggesting some degree of benefit (e.g., DiLorenzo et al., 2014; Marques et al., 2015). These supplements should be taken for a minimum of 2 weeks with $5 \mathrm{~g} /$ day of fish oil capsules (providing 3,500-mg eicosapentaenoic acid and 900-mg docosahexaenoic acid) to permit detectable increases in muscle n-3 PUFA lipid composition (McGlory et al., 2014). This level of n-3 PUFA supplementation is far in excess of what would be consumed in a typical diet and much greater than most suggested supplement regimes. Given that it is 
not possible to predict when an injury may occur, it could be suggested that athletes should take n-3 PUFA supplements on a regular basis; however, the long-term daily dose requires further investigation. Again, however, relying on findings from the exercise-induced muscle damage model to rule on a benefit of n-3 PUFA in macroscopic muscle injury prevention or recovery is speculative at this stage.

There are a number of other nutrients that have some rationale for supplementation to reduce the magnitude of muscle tissue injury and/or promote healing. Many of these nutrition strategies are claimed to work through either acting as an antioxidant or through a reduction in inflammation. In reality, unless there is a dietary deficiency, the vast majority of nutritional interventions have limited research to support such claims. Some of the most frequently studied and supplemented micronutrients to help with skeletal muscle injury are summarized in Table 1.

Finally, consideration must be given to the balance between muscle recovery and muscle adaptation. There is growing evidence that nutritional strategies that may assist with muscle recovery, such as anti-inflammatory and antioxidant strategies, may attenuate skeletal muscle adaptions (Owens et al., 2019). It would, therefore, be prudent to differentiate between an injury that requires time lost from the sport and typical exercise-induced muscle soreness when it comes to implementing a nutritional recovery strategy. Where adaptation comes before recovery, for example, in a preseason training phase, the best nutritional advice may simply to follow a regular diet and allow adaptations to occur naturally.

\section{Nutrition to Prevent and Treat Bone Injuries}

Stress fractures are common bone injuries suffered by athletes that have a different etiology than contact fractures, which also have a frequent occurrence, particularly in contact sports. Stress fractures are overuse injuries of the bone that are caused by the rhythmic and repeated application of mechanical loading in a subthreshold manner (McBryde, 1985). Given this, athletes involved in high- volume, high-intensity training, where the individual is body weight loaded, are particularly susceptible to developing a stress fracture (Fredericson et al., 2007), and training time lost can be significant (Ranson et al., 2010). The pathophysiology of stress fracture injuries is complex and not completely understood (Bennell et al., 1999), but some studies have suggested that nutritional inadequacies could be considered a risk factor (Moran et al., 2012). That said, there is little direct information relating to the role of diet and nutrition in either the prevention or recovery from bone injuries, such as stress fractures. As such, the completion of this article requires some extrapolation from the information relating to the effects of diet and nutrition on bone health in general.

Palacios (2006) provides a brief summary of some of the key nutrients for bone health, which include an adequate supply of calcium, protein, magnesium, phosphorus, vitamin D, potassium, and fluoride to directly support bone formation. Other nutrients important to support bone tissue include manganese, copper, boron, iron, zinc, vitamin $\mathrm{A}$, vitamin $\mathrm{K}$, vitamin $\mathrm{C}$, and the $\mathrm{B}$ vitamins. Silicon might also be added to this list of key nutrients for bone health. Given this, the consumption of dairy, fruits, and vegetables (particularly of the green leafy kind) are likely to be useful sources of the main nutrients that support bone health.

Of the more specific issues for the athlete, undoubtedly the biggest factor is the avoidance of low energy availability, which is essential to avoid negative consequences for bone (Papageorgiou et al., 2018a, 2018b). Ihle and Loucks (2004) were among the first to demonstrate this, showing that bone formation was reduced at an energy availability (EA) of $30 \mathrm{kcal} \cdot \mathrm{kg} \mathrm{LBM}^{-1} \cdot \mathrm{day}^{-1}$. More severe reductions in energy availability to $10 \mathrm{kcal} \cdot \mathrm{kg} \mathrm{LBM}^{-1} \cdot \mathrm{day}^{-1} \mathrm{had}$ the effect of both reducing bone formation and increasing bone resorption, likely initiating a dual negative effect on the bone. This seems like a serious problem, particularly if continued over time, given that some amenorrheic athletes have been reported to have energy availabilities of $\sim 16 \mathrm{kcal} \cdot \mathrm{kg} \mathrm{LBM}^{-1} \cdot \mathrm{day}^{-1}$ (Thong et al., 2000). Two studies from our own research group have used this level of energy availability and shown that 5 days of low EA

\section{Table 1 Nutritional Strategies Claimed to Help With Skeletal Muscle Injuries in Athletes}

\begin{tabular}{|c|c|c|c|}
\hline Micronutrient & Rationale for supplement & Suggested dose & Key research \\
\hline Vitamin D & $\begin{array}{l}\text { It is well established that many athletes are vitamin D deficient due } \\
\text { to a lack of sunlight exposure. Emerging evidence suggests that } \\
\text { vitamin D deficiencies can impair muscle regeneration following } \\
\text { damaging exercise both in vitro and in vivo. }\end{array}$ & $\begin{array}{l}2,000-4,000 \mathrm{IU} \mathrm{D} \text { taken daily } \\
\text { during the winter months to } \\
\text { ensure serum } 25(\mathrm{OH}) \mathrm{D} \text { is greater } \\
\text { than } 75 \mathrm{nmol} / \mathrm{L} \text { with sensible sun } \\
\text { exposure in the summer. }\end{array}$ & $\begin{array}{l}\text { Owens et al. (2015, } \\
\text { 2018) }\end{array}$ \\
\hline Vitamins $\mathrm{C}$ and $\mathrm{E}$ & $\begin{array}{l}\text { It has been claimed that increased free radical production increases } \\
\text { the magnitude of muscle damage following exercise and, therefore, } \\
\text { supplements with vitamins } \mathrm{C} \text { and E could increase recovery time. } \\
\text { Literature, however, indicates that vitamins } \mathrm{C} \text { and E have limited } \\
\text { ability to attenuate muscle damage or promote recovery. }\end{array}$ & $\begin{array}{l}\text { No need for additional } \\
\text { supplementation. }\end{array}$ & $\begin{array}{l}\text { Close et al. (2005); } \\
\text { Cobley et al. (2015); } \\
\text { Owens et al. (2019) }\end{array}$ \\
\hline Polyphenols & $\begin{array}{l}\text { It is claimed that polyphenols may attenuate muscle damage caused } \\
\text { by inflammation and increase free radical production. Montmorency } \\
\text { cherries (Prunus cerasus) are suggested to help improve rate of } \\
\text { muscle function recovery after damage as well as reduce muscle } \\
\text { soreness and inflammation, especially in athletes consuming a low } \\
\text { polyphenol diet. }\end{array}$ & $\begin{array}{l}\text { A diet rich in polyphenols (fruit } \\
\text { and vegetables) may be the best } \\
\text { strategy to augment recovery } \\
\text { from damaging exercise rather } \\
\text { than specific supplementation. }\end{array}$ & $\begin{array}{l}\text { Bell et al. (2015); } \\
\text { Peeling et al. (2018) }\end{array}$ \\
\hline Creatine & $\begin{array}{l}\text { Creatine monohydrate is one of the most widely used supplements to } \\
\text { support gains in strength and lean mass. Supplementation has been } \\
\text { shown to attenuate loss of upper arm muscle mass and strength } \\
\text { during limb immobilization, as well as increase muscle hypertrophy } \\
\text { following lower leg immobilization. }\end{array}$ & $\begin{array}{l}20 \mathrm{~g} / \text { day for } 5 \text { days followed by } \\
5 \mathrm{~g} / \text { day thereafter. }\end{array}$ & $\begin{array}{l}\text { Hespel et al. (2001); } \\
\text { Johnston et al. } \\
\text { (2009) }\end{array}$ \\
\hline
\end{tabular}


(15 kcal $\cdot \mathrm{kg} \mathrm{LBM}^{-1} \cdot \mathrm{day}^{-1}$ ) decreased bone formation and increased bone resorption in women, but not in men (although some men were affected; Papageorgiou et al., 2017). In athletes, this poses the question of whether the effect of low energy availability on bone is a result of dietary restriction or high exercise energy expenditures. Recently, the effects of 3 days low energy availability (at $15 \mathrm{kcal} \cdot \mathrm{kg} \mathrm{LBM}{ }^{-1} \cdot \mathrm{day}^{-1}$ ) achieved by diet or exercise on bone turnover markers in active, eumenorrheic women were examined (Papageorgiou et al., 2018b). Low EA achieved through inadequate dietary energy intake resulted in decreased bone formation but no change in bone resorption, whereas low EA achieved through exercise did not significantly influence bone metabolism, highlighting the importance of adequate dietary intakes for the athlete.

Evidence of the impact of low energy availability on bone health, particularly in female athletes, comes from the many studies relating to both the Female Athlete Triad (Nattiv et al., 2007) and Relative Energy Deficiency in Sport Syndromes (Mountjoy et al., 2014), with the latter also suggesting that this might also be an issue for male athletes. A thorough review of these syndromes is beyond the scope of the current article; however, those interested are advised to make use of the existing literature base on this topic. Maintaining an energy availability of $45 \mathrm{kcal} \cdot \mathrm{kg} \mathrm{LBM}^{-1} \cdot \mathrm{day}^{-1}$ over time is likely to be important in optimizing bone health in the athlete and, potentially, in helping to protect the bone against the development of bone injuries. That said, this is likely to be an unrealistic target for many athlete groups, particularly the endurance athlete (e.g., road cyclist, marathon runner or triathlete), whose energy expenditure during training is likely to be high, with a training schedule that limits the amount of time available for fueling. This target may also be difficult to achieve in youth athletes who have limited time to fuel given the combined demands of school and training. In addition, a calorie deficit is often considered to drive the endurance phenotype in these athletes, meaning that work is needed to identify the threshold of energy availability above which there are little or no negative implications for the bone. However, a recent case study on an elite female endurance athlete over a 9-year period demonstrated that it is possible to train slightly over optimal race weight and maintain sufficient energy availability for most of the year, and then reduce calorie intake to achieve race weight at specific times in the year (Stellingwerff, 2018). This may be the ideal strategy to allow athletes to race at their ideal weight, train at times with low energy availability to drive the endurance phenotype, but not be in a dangerously low energy availability all year round.

Moran et al. (2012) collected dietary intake data from military recruits at the start and end of basic training using food frequency questionnaires and compared the dietary intakes of the recruits who suffered a stress fracture $(n=12)$ with those who did not $(n=62)$. The development of stress fractures was associated with preexisting dietary deficiencies, not only in vitamin $\mathrm{D}$ and calcium, but also in carbohydrate intake. Although a small-scale association study, these data provide some indication of potential dietary risk factors for stress fracture injury. Miller et al. (2016) also demonstrated an increased risk of stress fracture in athletes with low vitamin D status, as assessed by circulating $25(\mathrm{OH}) \mathrm{D}_{3}$. Similarly, other groups have shown a link between calcium intake and both bone mineral density (Myburgh et al., 1990) and stress fracture risk (Nieves et al., 2010) in athletes. Conversely, improving vitamin D and calcium status with $800 \mathrm{IU} /$ day vitamin D and $2,000 \mathrm{mg}$ of calcium supplementation has been shown to reduce the risk of developing a stress fracture in military recruits (Lappe et al., 2008). Despite these initially encouraging findings, there remain relatively few prospective studies evaluating the optimal calcium and vitamin D intake in athletes relating to either (a) stress fracture prevention or (b) bone healing. For a more comprehensive review of this area, readers are directed toward a recent review by Fischer et al. (2018).

One further consideration that might need to be made with regard to the calcium intake of endurance athletes (and possibly weight classification athletes practicing dehydration strategies to make weight) is the amount of dermal calcium loss over time. Although the amount of dermal calcium lost with short-term exercise is unlikely to be that important in some endurance athletes performing prolonged exercise bouts or multiple sessions per day (e.g., triathletes), this could become an issue. Under these circumstances, athletes should consider either a high-calcium preexercise meal containing $1,300 \mathrm{mg}$ of calcium (Haakonssen et al., 2015) or a 1,000-mg calcium supplement (Barry et al., 2011), both of which have been shown to limit disturbances to calcium homeostasis and, potentially, the bone metabolic response to subsequent exercise.

Athletes are generally advised to consume more protein than the recommended daily allowance of $0.8 \mathrm{~g} \cdot \mathrm{kg} \mathrm{BM}^{-1} \cdot \mathrm{day}^{-1}$, with many athletes consuming 2-3 times this amount. Protein is a key constituent of the bone's structure, making up a substantial proportion of its mass and volume (Zimmermann et al., 2015). As such, it would seem logical to propose that dietary protein intake is important for bone health, but the role of protein (particularly animal protein sources) in bone health has been questioned, with some suggesting that it could be detrimental because of the acidic load that it creates; termed the "acid-ash hypothesis" (Barzel \& Massey, 1998). More recently, however, several reviews (Rizzoli et al., 2018) and meta-analyses (Shams-White et al., 2017, 2018) have opposed this view and have shown that there are no negative, and some beneficial, consequences of a high-protein intake for bone health, particularly when consuming adequate calcium.

Maintaining an appropriate dietary intake is important for maintaining fitness and health and/or in regaining fitness after injury in athletes. Conversely, inadequacies in dietary intake have a negative effect on physical performance, which might, in turn, contribute to an increased risk of injury. This is as likely to be the case for the bone as it is for other tissues of importance to the athlete, like muscles, tendons, and ligaments. Despite this, there is a relative dearth of information relating to the effects of dietary intake on bone health in athletes and, particularly, around the optimal diet to support recovery from bone injury. In the main, however, it is likely that the nutritional needs for bone health in the athlete are not likely to be substantially different from those of the general population, albeit with an additional need to minimize low energy availability states and consider the potentially elevated calcium, vitamin $\mathrm{D}$, and protein requirements of many athletes.

\section{Nutrition to Prevent and Treat Tendon and Ligament Injuries}

Tendinopathy is one of the most common musculoskeletal issues in high-jerk sports. Jerk, the rate of change of acceleration, is the physical property that coaches and athletes think of as plyometric load. Where the plyometric load is high across a tendon, such as for the patellar tendon in hurdlers and in the plant leg of jumpers and throwers, tendinopathy rates are high: approximately $30 \%$ and $45 \%$ for elite athletes, respectively (Lian et al., 2005). In support of the role of jerk in the development of tendinopathy, in distance 
runners, where jerk across the patellar tendon is lower, patellar tendinopathy rates are similarly lower $<15 \%$, whereas Achilles tendinopathy rates rise to $\sim 55 \%$ (Knobloch et al., 2008).

Given that the volume of high-jerk movements increases in elite athletes, interventions to prevent or treat tendinopathies would have a significant impact on elite performance. The goal of any intervention to treat tendinopathy is to increase the content of directionally oriented collagen and the density of cross-links within the protein to increase the tensile strength of the tendon. The most common intervention to treat tendinopathy is loading. The realization that tendons are dynamic tissues that respond to load began when the Kjaer laboratory demonstrated an increase in tendon collagen synthesis, in the form of increased collagen propeptides in the peritendinous space $72 \mathrm{hr}$ after exercise (Langberg et al., 1999). They followed this up using stable isotope infusion to show that tendon collagen synthesis doubled within the first $24 \mathrm{hr}$ after exercise (Miller et al., 2007). Therefore, loading can increase collagen synthesis, and this may contribute to the beneficial effects of loading on tendinopathy. Recently, combining loading with nutritional interventions has been proposed to further improve collagen synthesis (Shaw et al., 2017) and promote tendon and ligament healing (Baar, 2018), and this possibility will be discussed below.

\section{Vitamin C}

Nutrition has been recognized as being essential for collagen synthesis and tendon health for over 200 years. In the first controlled nutritional trial ever recorded (1747 AD), the Scot James Lind fed 12 sailors with scurvy one of six different interventions: no treatment, quart of cider, "twenty-five gulls" of vitriol, six spoonfuls of vinegar, half a pint of seawater, or two oranges and one lemon (Lind, 1757). The two sailors given the oranges and lemon recovered within 6 days; however, the relationship between the citrus fruit and scurvy continued to be debated for over 150 years. In 1959, Jerome Gross showed that guinea pigs on a vitamin $\mathrm{C}$ deficient diet did not synthesize collagen at a detectable level (Gross, 1959), making the molecular connection between vitamin $\mathrm{C}$ and scurvy. The requirement for vitamin $\mathrm{C}$ in the synthesis of collagen comes from its role in the regulation of prolyl hydroxylase activity (Mussini et al., 1967), an enzyme required for collagen cross-linking and export from the endoplasmic reticulum. As vitamin $\mathrm{C}$ is consumed in the hydroxylation reaction, and humans lack the L-gulono- $\gamma$-lactone oxidase enzyme required for the last step in the synthesis of vitamin C (Drouin et al., 2011), we need to consume $46 \mathrm{mg}$ /day to maintain normal collagen synthesis. Even though a basal level of vitamin $\mathrm{C}$ is required for collagen synthesis, whether exceeding this value results in a concomitant increase in collagen synthesis has yet to be determined. Therefore, currently, there is no evidence that increasing vitamin $\mathrm{C}$ intake will increase collagen synthesis and prevent tendon injuries.

\section{Copper}

Similar to vitamin C, copper is also required for enzymatic crosslinking of collagen through its role as a cofactor for the enzyme lysyl oxidase (Kagan \& Li, 2003). Like vitamin C, copper deficiency leads to impaired mechanical function of collagencontaining tissues, such as bone (Jonas et al., 1993), leading to an increase in fractures in people with copper deficiency (Paterson, 1988). However, the beneficial effects of copper are only seen in the transition from deficiency to sufficiency (Opsahl et al., 1982). There is no further increase in collagen function with increasing doses of copper. Therefore, the goal for copper intake should approximate the RDA of $\sim 1 \mathrm{mg} \cdot \mathrm{kg}^{-1} \cdot \mathrm{day}^{-1}$.

\section{Glycine}

Fibrillar collagens are a repeating tripeptide of glycine-X-proline/ hydroxyproline, where $\mathrm{X}$ represents any amino acid other than glycine and proline. This sequence allows collagen to form the tight triple helix that gives the protein its mechanical strength. Because of the importance of glycine, some researchers have hypothesized that increasing dietary glycine would have a beneficial effect on tendon healing. Vieira et al. (2015a) showed that 21 days after a collagenase injury to the Achilles tendon, rats on a diet containing $5 \%$ glycine demonstrated increased collagen and glycosaminoglycan content as well as mechanical strength. The authors repeated the results in a follow-up study (Vieira et al., 2015b), suggesting that glycine may aide in the recovery of tendon function after injury. However, consuming a diet where $5 \%$ of the calories come from glycine is not realistic in an athletic population.

\section{Gelatin/Hydrolyzed Collagen}

Another potential source of the amino acids found in collagen is gelatin or hydrolyzed collagen. Gelatin is created by boiling the skin, bones, tendons, and ligaments of cattle, pigs, and fish. Boiling releases large molecular weight $(>100 \mathrm{kDa})$ proteins that show limited solubility in water and form a gel after heating. Further chemical or enzymatic hydrolysis of gelatin breaks the protein into smaller peptides that are soluble in water and no longer form a gel. Because both gelatin and hydrolyzed collagen are derived from collagen, they are rich in glycine, proline, hydroxylysine, and hydroxyproline (Shaw et al., 2017). As would be expected from a dietary intervention that increases collagen synthesis, consumption of $10 \mathrm{~g}$ of hydrolyzed collagen in a randomized, double-blinded, placebo-controlled study in athletes decreased knee pain from standing and walking (Clark et al., 2008). The decrease in knee pain could be the result of an improvement in collagen synthesis of the cartilage within the knee since cartilage thickness, measured using gadolinium labeled magnetic resonance imaging, increases with long-term consumption of $10 \mathrm{~g}$ of hydrolyzed collagen (McAlindon et al., 2011). The role of gelatin consumption in collagen synthesis was directly tested by Shaw et al. (2017). In this randomized, double-blinded, placebo-controlled, crossover-designed study, subjects who consumed $15 \mathrm{~g}$ of gelatin showed twice the collagen synthesis, measured through serum propeptide levels, as either a placebo or a 5-g group. Furthermore, when serum from subjects fed either gelatin or collagen is added to engineered ligaments, the engineered ligaments demonstrate more than twofold greater mechanics and collagen content (Avey and Baar unpublished; Figure 1). Even though bathing the engineered ligaments in serum rich in procollagen amino acids provides a beneficial effect, this is a far cry from what would be seen in people. However, these data suggest that consuming gelatin or hydrolyzed collagen may increase collagen synthesis and potentially decrease injury rate in athletes.

\section{Other Nutrients}

There is a myriad of other nutrients that are purported to improve tendon/ligament function, including turmeric/curcumin, taurine, arginine, bromelain, or boswellic acid. These and other nutraceuticals have recently been reviewed by Fusini et al. (2016). Interestingly, many of these nutrients are thought to decrease inflammation, and the role of inflammation in tendinopathy in 

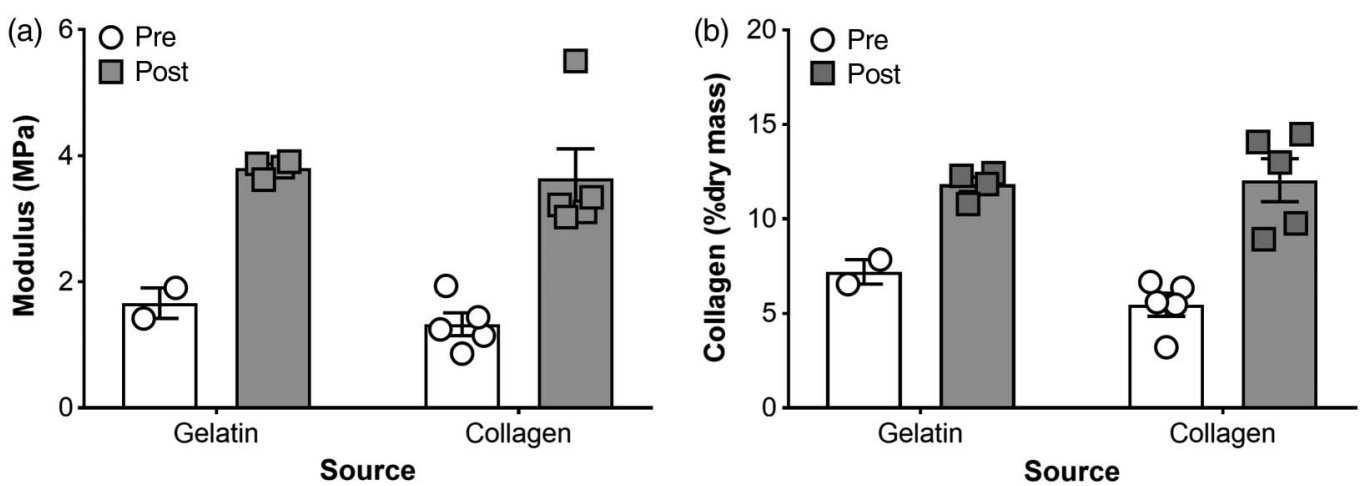

Figure 1 - Effect of serum isolated from an athlete before (open bars) or $1 \mathrm{hr}$ after (gray bars) consuming $15 \mathrm{~g}$ of either gelatin or hydrolyzed collagen and vitamin $\mathrm{C}$ on both (a) modulus (stiffness) and (b) percent collagen.

elite athletes remains controversial (Peeling et al., 2018). Therefore, future work is needed to validate these purported nutraceuticals in the prevention or treatment of tendon or ligament injuries.

\section{Conclusions}

Although injuries are going to happen in athletes, there are several nutrition solutions that can be implemented to reduce the risk and decrease recovery time. To reduce the risk of injury, it is crucial that athletes do not have chronic low energy availability, as this is a major risk factor for bone injuries. Cycling energy intake throughout the year to allow race weight to be achieved, while achieving adequate energy availability away from competitions, may be the most effective strategy. It is also crucial for bone, muscle, tendon, and ligament health to ensure that there are no dietary deficiencies, especially low protein intake or inadequate vitamin C, D, copper, n-3 PUFA, or calcium. This highlights the importance of athletes having access to qualified nutrition support to help them achieve their goals without compromising health. If an injury does occur, one of the key considerations during the injury is to ensure excessive lean muscle mass is not lost and that sufficient energy is consumed to allow repair, without significantly increasing body fat. It is crucial to understand the change in energy demands and, at the same time, ensure sufficient protein is consumed for repair, especially since the muscle could become anabolic resistant. In terms of tendon health, there is a growing interest in the role of gelatin to increase collagen synthesis. Studies are now showing that gelatin supplementation can improve cartilage thickness and decrease knee pain, and may reduce the risk of injury or accelerate return to play, providing both a prophylactic and therapeutic treatment for tendon, ligament, and, potentially, bone health. It should finally be emphasized that, where possible, all of these nutritional solutions should be explored in a "food first" manner, rather than a reliance on supplements (Peeling et al., 2018). Where supplementation is deemed necessary (e.g., diagnosed vitamin D deficiencies), athletes should seek appropriate advice from qualified staff with up-to-date knowledge of supplement contamination and anti-doping regulations. Last but not least, more human-based research is needed, ideally in elite athlete populations, on the possible benefits of some macro- and micronutrients in the prevention or boosted recovery of injured athletes. Given that placebocontrolled, randomized control trials are exceptionally difficult to perform in elite athletes (no athlete would want to be in a placebo group if there is a potential of benefit of an intervention, combined with the fact that the time course and pathology of the same injuries are often very different), it is important that high-quality case studies are now published in elite athletes to help to develop an evidence base for interventions.

\section{Acknowledgments}

All authors contributed equally to the manuscript, with each author writing specific sections and all authors editing the final manuscript prior to final submission. They also declare no conflicts of interest related to this manuscript.

\section{References}

Baar, K. (2018). Stress relaxation and targeted nutrition to treat patellar tendinopathy. International Journal of Sport Nutrition and Exercise Metabolism, 1-18. doi:10.1123/ijsnem.2018-0231

Barry, D.W., Hansen, K.C., van Pelt, R.E., Witten, M., Wolfe, P., \& Kohrt, W.M. (2011). Acute calcium ingestion attenuates exercise-induced disruption of calcium homeostasis. Medicine \& Science in Sports \& Exercise, 43, 617-623. PubMed ID: 20798655 doi:10.1249/MSS. 0b013e3181f79fa8

Barzel, U.S., \& Massey, L.K. (1998). Excess dietary protein can adversely affect bone. Journal of Nutrition, 128, 1051-1053. PubMed ID: 9614169 doi:10.1093/jn/128.6.1051

Bell, P.G., Walshe, I.H., Davison, G.W., Stevenson, E.J., \& Howatson, G. (2015). Recovery facilitation with Montmorency cherries following high-intensity, metabolically challenging exercise. Applied Physiology, Nutrition, and Metabolism, 40, 414-423. PubMed ID: 25794236 doi:10.1139/apnm-2014-0244

Bennell, K., Matheson, G., Meeuwisse, W., \& Brukner, P. (1999). Risk factors for stress fractures. Sports Medicine, 28, 91-122. PubMed ID: 10492029 doi:10.2165/00007256-199928020-00004

Blacker, S.D., Williams, N.C., Fallowfield, J.L., Bilzon, J., \& Willems, M.E. (2010). Carbohydrate vs. protein supplementation for recovery of neuromuscular function following prolonged load carriage. Journal of the International Society of Sports Nutrition, 7, 2. PubMed ID: 20157419 doi:10.1186/1550-2783-7-2

Buckley, J.D., Thomson, R.L., Coates, A.M., Howe, P.R., DeNichilo, M.O., \& Rowney, M.K. (2010). Supplementation with a whey protein hydrolysate enhances recovery of muscle force-generating capacity following eccentric exercise. Journal of Science and Medicine in Sport, 13, 178-181. PubMed ID: 18768358 doi:10.1016/j.jsams. 2008.06.007 
Clark, K.L., Sebastianelli, W., Flechsenhar, K.R., Aukermann, D.F., Meza, F., Millard, R.L., ... Albert, A. (2008). 24-Week study on the use of collagen hydrolysate as a dietary supplement in athletes with activityrelated joint pain. Current Medical Research \& Opinion, 24, 14851496. PubMed ID: 18416885 doi:10.1185/030079908X291967

Close, G.L., Ashton, T., McArdle, A., \& Maclaren, D.P. (2005). The emerging role of free radicals in delayed onset muscle soreness and contraction-induced muscle injury. Comparative Biochemistry and Physiology_Part A: Molecular \& Integrative Physiology, 142, 257-266. PubMed ID: 16153865 doi:10.1016/j.cbpa.2005.08.005

Cobley, J.N., McHardy, H., Morton, J.P., Nikolaidis, M.G., \& Close, G.L. (2015). Influence of vitamin $\mathrm{C}$ and vitamin $\mathrm{E}$ on redox signaling: Implications for exercise adaptations. Free Radical Biology \& Medicine, 84, 65-76. PubMed ID: 25841784 doi:10.1016/j.freeradbiomed. 2015.03.018

Cockburn, E., Stevenson, E., Hayes, P.R., Robson-Ansley, P., \& Howatson, G. (2010). Effect of milk-based carbohydrate-protein supplement timing on the attenuation of exercise-induced muscle damage. Applied Physiology, Nutrition, and Metabolism, 35, 270277. PubMed ID: 20555370 doi:10.1139/H10-017

DiLorenzo, F.M., Drager, C.J., \& Rankin, J.W. (2014). Docosahexaenoic acid affects markers of inflammation and muscle damage after eccentric exercise. The Journal of Strength and Conditioning Research, 28, 2768-2774. PubMed ID: 25029008 doi:10.1519/ JSC.0000000000000617

Drouin, G., Godin, J.R., \& Page, B. (2011). The genetics of vitamin C loss in vertebrates. Current Genomics, 12, 371-378. PubMed ID: 22294879 doi:10.2174/138920211796429736

Edouard, P., Branco, P., \& Alonso, J.M. (2016). Muscle injury is the principal injury type and hamstring muscle injury is the first injury diagnosis during top-level international athletics championships between 2007 and 2015. British Journal of Sports Medicine, 50, 619-630. PubMed ID: 26887415 doi:10.1136/bjsports-2015-095559

Edouard, P., Feddermann-Demont, N., Alonso, J.M., Branco, P., \& Junge, A. (2015). Sex differences in injury during top-level international athletics championships: Surveillance data from 14 championships between 2007 and 2014. British Journal of Sports Medicine, 49, 472-477. PubMed ID: 25618889 doi:10.1136/ bjsports-2014-094316

Feddermann-Demont, N., Junge, A., Edouard, P., Branco, P., \& Alonso, J.M. (2014). Injuries in 13 international Athletics championships between 2007-2012. British Journal of Sports Medicine, 48, 513522. PubMed ID: 24620039 doi:10.1136/bjsports-2013-093087

Fischer, V., Haffner-Luntzer, M., Amling, M., \& Ignatius, A. (2018). Calcium and vitamin D in bone fracture healing and post-traumatic bone turnover. European Cells \& Materials, 35, 365-385. PubMed ID: 29931664 doi:10.22203/eCM.v035a25

Frankenfield, D. (2006). Energy expenditure and protein requirements after traumatic injury. Nutrition in Clinical Practice, 21, 430-437. PubMed ID: 16998142 doi:10.1177/0115426506021005430

Fredericson, M., Chew, K., Ngo, J., Cleek, T., Kiratli, J., \& Cobb, K. (2007). Regional bone mineral density in male athletes: A comparison of soccer players, runners and controls. British Journal of Sports Medicine, 41, 664-668. PubMed ID: 17473003 doi:10.1136/bjsm. 2006.030783

Fusini, F., Bisicchia, S., Bottegoni, C., Gigante, A., Zanchini, F., \& Busilacchi, A. (2016). Nutraceutical supplement in the management of tendinopathies: A systematic review. Muscles, Ligaments and Tendons Journal, 6, 48-57. PubMed ID: 27331031

Gillen, J.B., Trommelen, J., Wardenaar, F.C., Brinkmans, N.Y., Versteegen, J.J., Jonvik, K.L., . . van Loon, L.J. (2017). Dietary protein intake and distribution patterns of well-trained Dutch athletes. International
Journal of Sport Nutrition and Exercise Metabolism, 27, 105-114. PubMed ID: 27710150 doi:10.1123/ijsnem.2016-0154

Glover, E.I., Phillips, S.M., Oates, B.R., Tang, J.E., Tarnopolsky, M.A., Selby, A., ... Rennie, M.J. (2008). Immobilization induces anabolic resistance in human myofibrillar protein synthesis with low and high dose amino acid infusion. The Journal of Physiology, 586, 60496061. PubMed ID: 18955382 doi:10.1113/jphysiol.2008.160333

Gross, J. (1959). Studies on the formation of collagen. IV. Effect of vitamin $\mathrm{C}$ deficiency on the neutral salt-extractible collagen of skin. Journal of Experimental Medicine, 109, 557-569. PubMed ID: 13654628 doi:10.1084/jem.109.6.557

Haakonssen, E.C., Ross, M.L., Knight, E.J., Cato, L.E., Nana, A., Wluka, A.E., ... Burke, L.M. (2015). The effects of a calcium-rich preexercise meal on biomarkers of calcium homeostasis in competitive female cyclists: A randomised crossover trial. PLoS ONE, 10, e0123302. PubMed ID: 25970439 doi:10.1371/journal.pone.0123302

Hespel, P., Op't Eijnde, B., Van Leemputte, M., Urso, B., Greenhaff, P.L., Labarque, V., ... Richter, E.A. (2001). Oral creatine supplementation facilitates the rehabilitation of disuse atrophy and alters the expression of muscle myogenic factors in humans. The Journal of Physiology, 536, 625-633. PubMed ID: 11600695 doi:10.1111/j. 1469-7793.2001.0625c.xd

Ihle, R., \& Loucks, A.B. (2004). Dose-response relationships between energy availability and bone turnover in young exercising women. Journal of Bone and Mineral Research, 19, 1231-1240. PubMed ID: 15231009 doi:10.1359/JBMR.040410

Impey, S.G., Hearris, M.A., Hammond, K.M., Bartlett, J.D., Louis, J., Close, G.L., \& Morton, J.P. (2018). Fuel for the work required: A theoretical framework for carbohydrate periodization and the glycogen threshold hypothesis. Sports Medicine, 48(5), 10311048. PubMed ID: 29453741 doi:10.1007/s40279-018-0867-7

Johnston, A.P., Burke, D.G., MacNeil, L.G., \& Candow, D.G. (2009). Effect of creatine supplementation during cast-induced immobilization on the preservation of muscle mass, strength, and endurance. The Journal of Strength and Conditioning Research, 23, 116-120. PubMed ID: 19130643 doi:10.1519/JSC.0b013e31818efbcc

Jonas, J., Burns, J., Abel, E.W., Cresswell, M.J., Strain, J.J., \& Paterson, C.R. (1993). Impaired mechanical strength of bone in experimental copper deficiency. Annals of Nutrition \& Metabolism, 37, 245-252. PubMed ID: 8311418 doi:10.1159/000177774

Kagan, H.M., \& Li, W. (2003). Lysyl oxidase: Properties, specificity, and biological roles inside and outside of the cell. Journal of Cellular Biochemistry, 88, 660-672. PubMed ID: 12577300 doi:10.1002/jcb. 10413

Knobloch, K., Yoon, U., \& Vogt, P.M. (2008). Acute and overuse injuries correlated to hours of training in master running athletes. Foot \& Ankle International, 29, 671-676. PubMed ID: 18785416 doi:10. 3113/FAI.2008.0671

Langberg, H., Skovgaard, D., Petersen, L.J., Bulow, J., \& Kjaer, M. (1999). Type I collagen synthesis and degradation in peritendinous tissue after exercise determined by microdialysis in humans. The Journal of Physiology, 521, 299-306. doi:10.1111/j.1469-7793. 1999.00299.x

Lappe, J., Cullen, D., Haynatzki, G., Recker, R., Ahlf, R., \& Thompson, K. (2008). Calcium and vitamin D supplementation decreases incidence of stress fractures in female navy recruits. Journal of Bone and Mineral Research, 23, 741-749. PubMed ID: 18433305 doi:10. 1359/jbmr.080102

Lian, O.B., Engebretsen, L., \& Bahr, R. (2005). Prevalence of jumper's knee among elite athletes from different sports: A cross-sectional study. American Journal of Sports Medicine, 33, 561-567. PubMed ID: 15722279 doi:10.1177/0363546504270454 
Lind, J. (1757). A treatise on the scurvy (2nd ed.). London, UK: A. Millar. Macnaughton, L.S., Wardle, S.L., Witard, O.C., McGlory, C., Hamilton, D.L., Jeromson, S., . . Tipton, K.D. (2016). The response of muscle protein synthesis following whole-body resistance exercise is greater following $40 \mathrm{~g}$ than $20 \mathrm{~g}$ of ingested whey protein. Physiological Reports, 4(15), e12893. PubMed ID: 27511985 doi:10.14814/phy2. 12893

Marques, C.G., Santos, V.C., Levada-Pires, A.C., Jacintho, T.M., Gorjao, R., Pithon-Curi, T.C., \& Cury-Boaventura, M.F. (2015). Effects of DHA-rich fish oil supplementation on the lipid profile, markers of muscle damage, and neutrophil function in wheelchair basketball athletes before and after acute exercise. Applied Physiology, Nutrition, and Metabolism, 40, 596-604. PubMed ID: 25942100 doi:10. 1139/apnm-2014-0140

McAlindon, T.E., Nuite, M., Krishnan, N., Ruthazer, R., Price, L.L., Burstein, D., ... Flechsenhar, K. (2011). Change in knee osteoarthritis cartilage detected by delayed gadolinium enhanced magnetic resonance imaging following treatment with collagen hydrolysate: A pilot randomized controlled trial. Osteoarthritis Cartilage, 19, 399405. PubMed ID: 21251991 doi:10.1016/j.joca.2011.01.001

McBryde, A.M., Jr. (1985). Stress fractures in runners. Clinical Sports Medicine, 4, 737-752.

McGlory, C., Galloway, S.D., Hamilton, D.L., McClintock, C., Breen, L., Dick, J.R., ... Tipton, K.D. (2014). Temporal changes in human skeletal muscle and blood lipid composition with fish oil supplementation. Prostaglandins, Leukotrienes \& Essential Fatty Acids, 90, 199-206. doi:10.1016/j.plefa.2014.03.001

Mettler, S., Mitchell, N., \& Tipton, K.D. (2010). Increased protein intake reduces lean body mass loss during weight loss in athletes. Medicine \& Science in Sports \& Exercise, 42, 326-337. PubMed ID: 19927027 doi:10.1249/MSS.0b013e3181b2ef8e

Miller, B.F., Hansen, M., Olesen, J.L., Schwarz, P., Babraj, J.A., Smith, K., ... Kjaer, M. (2007). Tendon collagen synthesis at rest and after exercise in women. Journal of Applied Physiology, 102, 541-546. PubMed ID: 16990502 doi:10.1152/japplphysiol.00797.2006

Miller, J.R., Dunn, K.W., Ciliberti, L.J., Jr., Patel, R.D., \& Swanson, B.A. (2016). Association of vitamin D with stress fractures: A retrospective cohort study. The Journal of Foot \& Ankle Surgery, 55, 117-120. PubMed ID: 26419854 doi:10.1053/j.jfas.2015.08.002

Milsom, J., Barreira, P., Burgess, D.J., Iqbal, Z., \& Morton, J.P. (2014). Case study: Muscle atrophy and hypertrophy in a premier league soccer player during rehabilitation from ACL injury. International Journal of Sport Nutrition and Exercise Metabolism, 24, 543-552. PubMed ID: 24458224 doi:10.1123/ijsnem.2013-0209

Moran, D.S., Heled, Y., Arbel, Y., Israeli, E., Finestone, A.S., Evans, R.K., \& Yanovich, R. (2012). Dietary intake and stress fractures among elite male combat recruits. Journal of the International Society of Sports Nutrition, 9, 6. PubMed ID: 22413851 doi:10.1186/15502783-9-6

Morton, R.W., Murphy, K.T., McKellar, S.R., Schoenfeld, B.J., Henselmans, M., Helms, E., ... Phillips, S.M. (2018). A systematic review, meta-analysis and meta-regression of the effect of protein supplementation on resistance training-induced gains in muscle mass and strength in healthy adults. British Journal of Sports Medicine, 52, 376-384. PubMed ID: 28698222

Mountjoy, M., Sundgot-Borgen, J., Burke, L., Carter, S., Constantini, N., Lebrun, C., ... Ljungqvist, A. (2014). The IOC consensus statement: Beyond the female athlete triad-Relative Energy Deficiency in Sport (RED-S). British Journal of Sports Medicine, 48, 491-497. PubMed ID: 24620037 doi:10.1136/bjsports-2014-093502

Mussini, E., Hutton, J.J., Jr., \& Udenfriend, S. (1967). Collagen proline hydroxylase in wound healing, granuloma formation, scurvy, and growth. Science, 157, 927-929. PubMed ID: 4378050 doi:10.1126/ science.157.3791.927

Myburgh, K.H., Hutchins, J., Fataar, A.B., Hough, S.F., \& Noakes, T.D. (1990). Low bone density is an etiologic factor for stress fractures in athletes. Annals of Internal Medicine, 113, 754-759. PubMed ID: 1978620 doi:10.7326/0003-4819-113-10-754

Nattiv, A., Loucks, A.B., Manore, M.M., Sanborn, C.F., Sundgot-Borgen, J., Warren, M.P., and American College of Sports Medicine. (2007). American College of Sports Medicine position stand. The female athlete triad. Medicine \& Science in Sports \& Exercise, 39, 18671882. PubMed ID: 17909417 doi:10.1249/mss.0b013e318149f111

Nieves, J.W., Melsop, K., Curtis, M., Kelsey, J.L., Bachrach, L.K., Greendale, G., ... Sainani, K.L. (2010). Nutritional factors that influence change in bone density and stress fracture risk among young female cross-country runners. Physical Medicine and Rehabilitation, 2, 740-750.

Nosaka, K., Sacco, P., \& Mawatari, K. (2006). Effects of amino acid supplementation on muscle soreness and damage. International Journal of Sport Nutrition and Exercise Metabolism, 16, 620-635. PubMed ID: 17342883 doi:10.1123/ijsnem.16.6.620

Opsahl, W., Zeronian, H., Ellison, M., Lewis, D., Rucker, R.B., \& Riggins, R.S. (1982). Role of copper in collagen cross-linking and its influence on selected mechanical properties of chick bone and tendon. Journal of Nutrition, 112, 708-716. PubMed ID: 6121843 doi:10.1093/jn/ 112.4.708

Owens, D.J., Allison, R., \& Close, G.L. (2018). Vitamin D and the athlete: Current perspectives and new challenges. Sports Medicine, 48, 3-16. PubMed ID: 29368183 doi:10.1007/s40279-017-0841-9

Owens, D.J., Sharples, A.P., Polydorou, I., Alwan, N., Donovan, T.F., Tang, J., ... Close, G.L. (2015). A systems based investigation into vitamin D and skeletal muscle repair, regeneration and hypertrophy. American Journal of Physiology-Endocrinology and Metabolism, 309, E1019-E1031. PubMed ID: 26506852 doi:10.1152/ajpendo. 00375.2015

Owens, D.J., Twist, C., Cobley, J.N., Howatson, G., \& Close, G.L. (2019). Exercise-induced muscle damage: What is it, what causes it and what are the nutritional solutions? European Journal of Sport Science, 19(1), 71-85. doi:10.1080/17461391.2018.1505957

Palacios, C. (2006). The role of nutrients in bone health, from A to Z. Critical Reviews in Food Science and Nutrition, 46, 621-628. PubMed ID: 17092827 doi:10.1080/10408390500466174

Papageorgiou, M., Dolan, E., Elliott-Sale, K.J., \& Sale, C. (2018a). Reduced energy availability: Implications for bone health in physically active populations. European Journal of Nutrition, 57, 847-859. doi:10.1007/s00394-017-1498-8

Papageorgiou, M., Elliott-Sale, K.J., Parsons, A., Tang, J.C.Y., Greeves, J.P., Fraser, W.D., \& Sale, C. (2017). Effects of reduced energy availability on bone metabolism in women and men. Bone, 105, 191199. PubMed ID: 28847532 doi:10.1016/j.bone.2017.08.019

Papageorgiou, M., Martin, D., Colgan, H., Cooper, S., Greeves, J.P., Tang, J.C.Y., ... Sale, C. (2018b). Bone metabolic responses to low energy availability achieved by diet or exercise in active eumenorrheic women. Bone, 114, 181-188. doi:10.1016/j.bone.2018.06.016

Pasiakos, S.M., Lieberman, H.R., \& McLellan, T.M. (2014). Effects of protein supplements on muscle damage, soreness and recovery of muscle function and physical performance: A systematic review. Sports Medicine, 44, 655-670. PubMed ID: 24435468 doi:10.1007/ s40279-013-0137-7

Paterson, C.R. (1988). Collagen chemistry and the brittle bone diseases. Endeavour, 12, 56-59. PubMed ID: 2458906

Peeling, P., Binnie, M.J., Goods, P.S.R., Sim, M., \& Burke, L.M. (2018). Evidence-based supplements for the enhancement of athletic 
performance. International Journal of Sport Nutrition and Exercise Metabolism, 28(2), 178-187. PubMed ID: 29465269 doi:10.1123/ ijsnem.2017-0343

Phillips, S.M. (2012). Dietary protein requirements and adaptive advantages in athletes. British Journal of Nutrition, 108(Suppl. 2), S158-S167.

Phillips, S.M., \& Van Loon, L.J. (2011). Dietary protein for athletes: From requirements to optimum adaptation. Journal of Sports Sciences, 29(Suppl. 1), S29-S38. doi:10.1017/S0007114512002516

Ranson, C.A., Burnett, A.F., \& Kerslake, R.W. (2010). Injuries to the lower back in elite fast bowlers: Acute stress changes on MRI predict stress fracture. Journal of Bone and Joint Surgery-British, 92, 1664-1668. doi:10.1302/0301-620X.92B12.24913

Rizzoli, R., Biver, E., Bonjour, J.P., Coxam, V., Goltzman, D., Kanis, J.A., ... Reginster, J.Y. (2018). Benefits and safety of dietary protein for bone health-An expert consensus paper endorsed by the European Society for Clinical and Economical Aspects of Osteopororosis, Osteoarthritis, and Musculoskeletal Diseases and by the International Osteoporosis Foundation. Osteoporosis International. PubMed ID: 29740667 doi:10.1007/s00198-018-4534-5

Shams-White, M.M., Chung, M., Du, M., Fu, Z., Insogna, K.L., Karlsen, M.C., ... Weaver, C.M. (2017). Dietary protein and bone health: A systematic review and meta-analysis from the National Osteoporosis Foundation. The American Journal of Clinical Nutrition, 105, 15281543. PubMed ID: 28404575 doi:10.3945/ajcn.116.145110

Shams-White, M.M., Chung, M., Fu, Z., Insogna, K.L., Karlsen, M.C., LeBoff, M.S., .. . Weaver, C.M. (2018). Animal versus plant protein and adult bone health: A systematic review and meta-analysis from the National Osteoporosis Foundation. PLoS ONE, 13, e0192459. PubMed ID: 29474360 doi:10.1371/journal.pone.0192459

Shaw, G., Lee-Barthel, A., Ross, M.L., Wang, B., \& Baar, K. (2017). Vitamin C-enriched gelatin supplementation before intermittent activity augments collagen synthesis. The American Journal of Clinical Nutrition, 105, 136-143. PubMed ID: 27852613 doi:10. 3945/ajcn.116.138594

Stellingwerff, T. (2018). Case study: Body composition periodization in an Olympic-level female middle-distance runner over a 9-year career. International Journal of Sport Nutrition and Exercise Metabolism, 28, 428-433. PubMed ID: 29140157 doi:10.1123/ijsnem.2017-0312

Stokes, T., Hector, A.J., Morton, R.W., McGlory, C., \& Phillips, S.M. (2018). Recent perspectives regarding the role of dietary protein for the promotion of muscle hypertrophy with resistance exercise training. Nutrients, 10(2), E180. PubMed ID: 29414855 doi:10.3390/ nu10020180
Thong, F.S., McLean, C., \& Graham, T.E. (2000). Plasma leptin in female athletes: relationship with body fat, reproductive, nutritional, and endocrine factors. Journal of Applied Physiology, 88(6), 2037-2044.

Timpka, T., Jacobsson, J., Bargoria, V., Periard, J.D., Racinais, S., Ronsen, O., ... Alonso, J.M. (2017). Preparticipation predictors for championship injury and illness: Cohort study at the Beijing 2015 International Association of Athletics Federations World Championships. British Journal of Sports Medicine, 51, 271-276. PubMed ID: 27827793 doi:10.1136/bjsports-2016-096580

Tipton, K.D., Borsheim, E., Wolf, S.E., Sanford, A.P., \& Wolfe, R.R. (2003). Acute response of net muscle protein balance reflects 24-h balance after exercise and amino acid ingestion. American Journal of Physiology-Endocrinology and Metabolism, 284, E76-E89. PubMed ID: 12388164 doi:10.1152/ajpendo.00234.2002

Tipton, K.D., \& Phillips, S.M. (2013). Dietary protein for muscle hypertrophy. Nestlé Nutrition Institute Workshop Series, 76, 73-84. PubMed ID: 30256501 doi:10.1159/000350259

Vieira, C.P., De Oliveira, L.P., Da Re Guerra, F., Dos Santos De Almeida, M., Marcondes, M.C., \& Pimentel, E.R. (2015a). Glycine improves biochemical and biomechanical properties following inflammation of the achilles tendon. The Anatomical Record, 298, 538-545. doi:10. 1002/ar.23041

Vieira, C.P., Guerra Fda, R., de Oliveira, L.P., Almeida, M.S., Marcondes, M.C., \& Pimentell, E.R. (2015b). Green tea and glycine aid in the recovery of tendinitis of the Achilles tendon of rats. Connective Tissue Research, 56, 50-58. doi:10.3109/03008207.2014.983270

Wall, B.T., Snijders, T., Senden, J.M., Ottenbros, C.L., Gijsen, A.P., Verdijk, L.B., \& van Loon, L.J. (2013). Disuse impairs the muscle protein synthetic response to protein ingestion in healthy men. The Journal of Clinical Endocrinology \& Metabolism, 98, 4872-4881. PubMed ID: 24108315 doi:10.1210/jc.2013-2098

Waters, R.L., Campbell, J., \& Perry, J. (1987). Energy cost of three-point crutch ambulation in fracture patients. Journal of Orthopaedic Trauma, 1, 170-173. PubMed ID: 3506593

Wojcik, J.R., Walber-Rankin, J., Smith, L.L., \& Gwazdauskas, F.C. (2001). Comparison of carbohydrate and milk-based beverages on muscle damage and glycogen following exercise. International Journal of Sport Nutrition and Exercise Metabolism, 11, 406-419. PubMed ID: 11915776

Zimmermann, E.A., Busse, B., \& Ritchie, R.O. (2015). The fracture mechanics of human bone: Influence of disease and treatment. Bonekey Reports, 4, 743. PubMed ID: 26380080 doi:10.1038/bonekey. 2015.112 